\title{
Can ionic diffusion have an effect on extracellular potentials?
}

\author{
Geir Halnes ${ }^{1 *}$, Tuomo Mäki-Marttunen², Klas H Pettersen ${ }^{3}$, Daniel Keller ${ }^{4}$, Ole A Andreassen ${ }^{2}$, Gaute T Einevoll ${ }^{1,5}$ \\ From 24th Annual Computational Neuroscience Meeting: CNS*2015 \\ Prague, Czech Republic. 18-23 July 2015
}

Several pathological conditions, such as hypoxia, anoxia, ischemia and spreading depression are associated with ion concentration changes in the extracellular space (ECS) [1]. Also during non-pathological conditions, endured periods of intense neural signaling may cause local ion concentration changes in the millimolar range. Changes in ion concentrations are often accompanied by a slow negative potential shift measured in the ECS [1-3], the origin of which is not properly understood. In computational neuroscience, it is common to use the simplifying assumption that diffusive currents (along concentration gradients) are negligible compared to Ohmic currents (along electrical fields). This is, for example, an underlying assumption in the cable equation used in most multi-compartmental neural models. It is also an underlying assumption in standard current source density (CSD) theory, which predicts neural current sources from recordings of extracellular potentials. However, theoretical studies have identified scenarios where large, but biologically realistic, ion concentration gradients may induce diffusive currents that are comparable in magnitude to Ohmic currents [4,5].

In the current work, we have explored possible effects that diffusive currents may have on the extracellular potential in a cortical column. To do this, we developed a hybrid simulation framework: First, we used the simulator NEURON (and an available multicompartmental neural model with realistic morphology [6]) to simulate the transmembrane ionic output from a small population of cortical neurons driven by realistic synaptic input. Next, we used a separate scheme to predict variations in extracellular potentials and ion concentrations. The scheme was based on the Nernst-Planck equations

\footnotetext{
* Correspondence: geir.halnes@nmbu.no

'Dept. of Mathematical Sciences and Technology, Norwegian University of Life Sciences, Ås, Norway

Full list of author information is available at the end of the article
}

for electrodiffusion and the constraint of electroneutrality, and represents a novel, efficient and generally applicable method for simulating extracellular dynamics surrounding multicompartmental neural models or networks of such (e.g., the Blue Brain simulator).

Our key findings were: (i) Morphology-dependent distributions of transmembrane current sources/sinks induced sustained extracellular potentials. Spatial variations of the ECS potential were of the order of a few $\mathrm{mV}$ across the depth of the cortical columns, which is similar to experimentally observed sustained potential profiles $[2,3]$. (ii) Long periods of neuronal output (simulations were run for $80 \mathrm{~s}$ ) could change local ECS ion concentrations by several millimolars. (iii) For large, but realistic, concentration gradients in the ECS, diffusive currents were of the same magnitude as Ohmic currents. (iv) Diffusive currents could have a significant impact on the sustained extracellular potentials, and could be a possible explanation to the observed relationship between ionic shifts and voltage drops in the ECS [1-3]. (v) Variation in concentrations and diffusive currents took place at the time scale of several seconds, and had little impact on the frequencies that are of predominant interest in standard CSD-analysis.

\section{Authors' details \\ ${ }^{1}$ Dept. of Mathematical Sciences and Technology, Norwegian University of Life Sciences, Ås, Norway. ${ }^{2}$ NORMENT, Institute of Clinical Medicine, University of Oslo, Oslo, Norway. ${ }^{3}$ Centre for Molecular Medicine Norway, University of Oslo, Oslo, Norway. ${ }^{4}$ The Blue Brain Project, EPFL, Lausanne, Switzerland. ${ }^{5}$ Department of Physics, University of Oslo, Oslo, Norway.}

Published: 18 December 2015

\section{References \\ 1. Syková E, Nicholson C: Diffusion in Brain Extracellular Space. Physiol Rev 2008, 88:1277-1340. \\ 2. Cordingley $G$, Somjen $G$ : The clearing of excess potassium from extracellular space in spinal cord and cerebral cortex. Brain Research 1978, 151:291-306.}


3. Dietzel I, Heinemann U, Lux H: Relations between slow extracellular potential changes, glial potassium buffering, and electrolyte and cellular volume changes during neuronal hyperactivity in cat. Glia 1989, 2:25-44.

4. Qian N, Sejnowski T: An electro-diffusion model for computing membrane potentials and ionic concentrations in branching dendrites, spines and axons. Biological Cybernetics 1989, 15:1-15.

5. Halnes G, Østby I, Pettersen KH, Omholt SW, Einevoll GT: Electrodiffusive model for astrocytic and neuronal ion concentration dynamics. PLOS Computational Biology 2013, 9(12):e1003386.

6. Hay E, Hill S, Schürmann F, Markram H, Segev I: Models of neocortical layer $5 \mathrm{~b}$ pyramidal cells capturing a wide range of dendritic and perisomatic active properties. PLoS Computational Biology 2011, 7(7): e1002107.

doi:10.1186/1471-2202-16-S1-P68

Cite this article as: Halnes et al:: Can ionic diffusion have an effect on extracellular potentials? BMC Neuroscience 2015 16(Suppl 1):P68.

\section{Submit your next manuscript to BioMed Central} and take full advantage of:

- Convenient online submission

- Thorough peer review

- No space constraints or color figure charges

- Immediate publication on acceptance

- Inclusion in PubMed, CAS, Scopus and Google Scholar

- Research which is freely available for redistribution

Submit your manuscript at www.biomedcentral.com/submit
Ciomed Central 